\title{
Power and space in the drone age: a literature review and politico-geographical research agenda
}

\author{
F. Klauser and S. Pedrozo \\ Institut de Géographie, Université de Neuchâtel, Neuchâtel, Switzerland \\ Correspondence to: F. Klauser (francisco.klauser@unine.ch)
}

Received: 27 March 2015 - Accepted: 24 August 2015 - Published: 8 October 2015

\begin{abstract}
Camera-fitted drones are now easily affordable to the public. The resulting proliferation of the aerial gaze raises a series of critical issues, ranging from the changing regimes of visibility across urban and rural space to the novel risks and dynamics of control implied by current drone developments. The paper argues that a distinct "spatial curiosity" and "power sensitivity" are required if we are to grasp and explore these issues. On this basis, and grounded in an extensive literature review, the paper outlines a politico-geographical research agenda for the investigation of the making, functioning and implications of drone systems. Such an agenda, it is claimed, could afford deepened insight into the driving forces that are behind current drone developments, would show how drones work in different institutional contexts, and could highlight how drones impact on the envisioned reality. This in turn would provide a deepened understanding of the "politics of visibility", "politics of the air" and "politics of the ground" conveyed by drones, and open up a wider conceptual reflection on the role of the aerial dimension in the projection of power across and within space.
\end{abstract}

\section{Introduction}

Drone technology has become smaller and much more affordable. Originally developed for military purposes (Graham, 2010), drones now have manifold civil applications and can be flown with little to no training. This development has gained great momentum especially since the start of the 21st century (Rothstein, 2015). Consider the case of Switzerland, which is symptomatic in this respect: used since 2001 by the Swiss armed forces (Fleury, 2013), drones have repeatedly made national headlines in recent years as tools for policing and law enforcement (Canal, 2014; RTS, 2014), border control (Gessat, 2012), environmental monitoring (Turrettini, 2013), scientific research (Brouet, 2014), mapping (Delaye, 2013; Rey-Mermet, 2013), disaster relief (Duruz, 2014), and traffic management (Baconnet, 2014; Brouet, 2014). Furthermore, many people have now begun flying drones recreationally, whilst companies specializing in aerial photography and mapping have also become big drone users. Overall, more than 20000 drones are currently estimated to be in use in Switzerland (Sacco, 2014), while globally, the market potential of military and civil drones is estimated at 89000 billion dollars for the period of 2013 to 2021 (Homeland Security News Wire, 2011).

There is now a growing social-scientific literature that focuses on drones in military conflict (e.g. Chamayou, 2013; Gregory, 2011). In contrast, civil and commercial applications of drones have remained widely unnoticed in academic research. In reaction to this, we outline a broader research agenda for the investigation of both civil and military drones, fitted with imaging capabilities. Thus the technology is not only set in relation to the fields of war, risk and security, but approached more broadly in its protective, administrative and more playful and entertaining functions. Hereby, we place centrally the conveyed capabilities of vision and visualization from above. This thematic focus gives direction to our discussion, whilst also aiming to avoid a duplication of the already existing accounts that emphasise the "ability to kill" of drones deployed in armed conflict (Adey et al., 2011; Williams, 2007).

Importantly, we also adopt a specific disciplinary perspective in the present paper, in asking for a distinct "spatial curiosity" and "power sensitivity" for the investigation of drones. The paper thus opens up a reflection on the pos- 
sibility of a specifically politico-geographical approach to the drone problematic, if we perceive political geography to be the academic field that studies power and space in their co-constitutive and mediated relationship (Cox et al., 2008; Painter, 2008; Raffestin, 1980).

In what follows, we first offer an overview of the existing grey literature in the field, which here refers to all publications on the drone problematic that have not been peerreviewed or produced by a commercial publisher. This clarifies a series of terminological and definitional issues, allows the discussion of differing drone types, practices and applications, highlights some critical issues connected with the use of drones and thus underlines the importance of the research we claim should be undertaken. Second, we discuss the social-scientific literature currently available on the problematic. This aligns with our ambition to set out a specifically politico-geographical research agenda on drones, as we here work out a basic understanding of drones as aerial techniques of power that are intrinsically bound up with space. Third, and stemming from the preceding literature review, we outline a series of research problems and questions that should be explored in future academic work. These are situated on three broad analytical levels, referring to the (1) making, (2) functioning, and (3) implications of drones, whilst also pointing at the more general conceptual task of reconsidering the concepts of "airspace" and "airpower", and of exploring the interactions between the two.

\section{Grey literature on the drone problematic}

The spread of drone technology in the 21st century has sparked a revealing, if still rather limited, literature that has sought to examine the modalities and technicalities of the deployed aircrafts, and to reflect upon the implications of the extended and redefined possibilities of vision and visualization from above. There are at least three main aspects to highlight from this body of work.

A first point relates to the terminology used to describe the concept of unmanned flying machines, which varies considerably across differing literature, linguistic contexts and milieux (Pedrozo, 2014). In consideration of accounting for the terminological choice of the paper, it is worth reviewing here the six most common terms. The first is UAV, which appears in the 1990s and stands for "unmanned aerial vehicle". It is mainly associated with the technological advances of that decade, such as GPS and radar imagery, which transmit data remotely and without an on-board pilot (Zubeldia, 2012). The second is UAS, or "unmanned aircraft system", which appears in the early 2000s. This time is marked by the digitization of the battlefield (Mayfield, 1996), which invites an understanding of unmanned aircraft as part of wider informational command and control systems for military purposes (Zubeldia, 2012). Since 2005, the acronym RPA (remotely piloted aircraft) has also been used, especially in the mili- tary context (Birmingham Policy Commission, 2014), stressing the presence of operators who control the aircraft from the ground. The fifth acronym, RPAS, comes from the International Civil Aviation Organization, meaning "remotely piloted aircraft system". This brings together the main aspects associated with the two aforementioned terms; namely, that unmanned aircraft require some command and control links, whilst also relying on many other components that together form a complex system (Office of the Privacy Commissioner of Canada, 2013). Finally, the sixth term is that of "drones", which is the popular term used in the Anglophone world for any type of vehicle, including aircraft, characterized by the absence of an on-board pilot and either autonomous or piloted from the ground (Asencio, 2008; Gregory, 2011; Moulard and Grozel, 2008). In Switzerland, France and Germany, "drone" is also the most widely used term both in civil society and amongst public and private drone users (Zubeldia, 2012). Thus this sixth term, "drones", is the one that best fits the context of our discussion.

A second aspect to stress relates to the wide and heterogeneous range of aerial vehicles that are named drones or subsumed under related notions (Rothstein, 2015). This highlights the large variety of sizes and configurations of drones, which can be as small as an insect, or as large as a small commercial airliner (Bracken-Roche et al., 2014). Drones can be part of advanced military systems, or devices for leisure and fun. They can be fitted with advanced surveillance technologies, and augmented with analytics software that enables the automated tracking of specific objects (Office of the Privacy Commissioner of Canada, 2013). Reflecting the varying applications and capabilities of the technology, there are also different typologies of drones in existing literature, which we can however not be discussed in detail here (for such a discussion see Office of the Privacy Commissioner of Canada, 2013; United States Government Accountability Office, 2012).

A third aspect to retain from the existing literature revolves around the opportunities and problems that arise from contemporary drone practices. On the one hand, drones are often described as presenting advantages over manned aircraft, in that they are cheaper, more flexible and easier to deploy, whilst also being risk free for pilots, especially when used in military operations (United States Government Accountability Office, 2012). On the other hand, critical issues range from privacy and security concerns (due to the potential for drone accidents and terrorist strikes, for example) to the novel dynamics of power, counterpower and resistance implied by contemporary drone developments (Goodman, 2013; Bracken-Roche et al., 2014). In recent years, there has thus emerged a rapidly developing body of work that focuses especially on the ethical (British Ministry of Defence, 2011; Geiger, 2011; Gettinger et al., 2014; Valavanis and Vachtsevanos, 2015) and legal challenges associated with drones (Finn and Wright, 2012; Stanley and Crump, 2011; Information and Privacy Commissioner, 2012). 
Literature on the opportunities and problems associated with drones also highlights critical issues that arise from the transfer of drone technology from the military to the civil domain. Relevant discussions often inscribe the drone problematic within wider questions centring on the proliferation and normalization of military technologies, expertise and doctrines in the fields of policing and border control, and on the implications this has for homeland security and for everyday social life more generally (Graham, 2010; Wall, 2013; Wall and Monahan, 2011). Furthermore, drones have been portrayed as catalysts that contribute to the development of novel inter-organizational relationships that blur the traditional distinctions between the civil and military contexts, war and law enforcement, and internal and external security. In Switzerland, for example, such debates emerged around the deployment of drones for the monitoring of urban space at the European Football Championships 2008 (Schweizer Armee, 2008). More recently, controversy has arisen over the planned purchase of field-tested Israeli drones for border control and public safety purposes (Lauener, 2014). Thus issues surrounding the interactions and interdependencies between civil and military spheres appear to arise predominantly in connection with drone systems deployed for policing and public-safety purposes.

\section{Academic literature}

Whilst a lot of work on drones is merely descriptive and interested in but a few specific aspects or issues connected with the problematic, there has also in recent years emerged an increasingly sophisticated academic literature that offers a range of more conceptually driven analyses. The following review of this literature is structured into three main parts, distinguishing between the "politics of visibility", the "politics of the air" and the "politics of the ground" conveyed by drones.

This framing of our discussion offers two main advantages. On the one hand, it provides an initial understanding of drones as aerial techniques of vision and visualization that are intrinsically bound up with space. On the other hand, the three topics of the politics of visibility, politics of the air and politics of the ground are to be considered as a series of crosscutting, drone-related problematics that run through the research questions and objectives outlined in Sect. 4 of the paper. Scholarship may be strengthened by addressing these problematics in closer empirical detail (for example through the investigation of specific case studies), so as to elucidate the problems and benefits arising from the proliferating use of drones in the present-day world.

\subsection{Politics of visibility}

Academic literature has added remarkably to the understanding of the politics of visibility conveyed by drones, thus inviting a research focus on the power dynamics unfolding from the technology's visual and visualizing capabilities. Referring to the seemingly unhindered, easily adaptable and "persistently present" (Williams, 2011b) drone gaze that allows the operators to "see a multiplicity of renderings of the area targeted" (Williams, 2011a, b), some scholars and commentators go so far as to ascribe panoptical prowess to drones (Clarke, 2014; Nimmo, 2013). Yet, as shown by Williams (2011a,b) and Gregory (2011), for example, the visual power of drones also needs to be relativized in that drones are themselves fundamentally limited and inherently vulnerable, depending on the interplay between the different human and non-human entities assembled around each system. If drones permit novel forms of vision and visualization, these in turn reflect the technical capabilities, the underpinning interests and the multiple coalitions of authority and expertise through which the systems are co-produced (Adey et al., 2011).

This point is of fundamental importance from both a political and an empirical viewpoint. Politically speaking, in debating and administering particular drone projects, the focus cannot be restricted to whether specific technologies are useful and desirable per se, but attention should be paid to the interplay between the different human and non-human, social and technical entities assembled. Who will be using the drones and the information generated, and how? What interests and rationales are involved and how are these shaping and in turn shaped by the functionalities of the deployed technologies? How exactly will specific technologies modify existing practices of vision and visualization, and how will they affect the exchanges between the actors involved? Studying such questions is essential for an understanding of the benefits and problems implied by current drone developments. The necessary empirical response to such an understanding of drones is the detailed study of the interplays between the involved "actants" (Latour, 2005) in the planning, conception, development, and operation of particular drone systems.

Whilst scholars differ in their assessment of the visual prowess of drones, all of the aforementioned literature invites a focus on drones as remote "vision machines" (Virilio, 2000) that offer novel abilities to see and visualise, and as such also allow new ways of monitoring and control. Thus the problematic can be connected neatly with wider considerations about the changing regimes of surveillance and visibility that characterise the present-day world (Murakami Wood et al., 2006; Wise and Koskela, 2013). Yet in the present paper, the term "surveillance" itself is not suggested to be mobilized as a conceptual lens or framing tool, for by definition it implies a routine and systematic activity of information gathering, transfer, and analysis (Lyon, 2007). This is often not the case with drones. Private and commercial drone usage for example the filming of events or the deployment of drones for fun - is sporadic and punctual rather than well-ordered and sequential or systematic. Approaching drones as techniques of vision and visualization, rather than as techniques of surveillance, allows a wider focus that remains open to the unsystematic visibilities created by drones, as increasingly 
mass-marketed devices in manifold public and private use. One of the key questions that need to be addressed in future research is indeed how visibility becomes in new ways a social and a political issue as a result of the proliferating use of drones.

\subsection{Politics of the air}

A second theme that runs through the existing academic work on drones is that of the "politics of the air". Connecting with the emerging "aerial turn" in critical human geography (Adey, 2010), this theme extends the previous one in that drones are here not only approached as techniques of vision and visualization, but also set in explicit relation to the airspace in which they operate. There are three sub-themes to highlight.

Firstly, there is an interesting body of work that navigates around the combined questions of how drones inhabit and contribute to perform the airspace in which they operate, and of how in turn this airspace, as a carefully managed and defended socio-political reality, affects the many forms of drone use (Williams, 2011a, b, 2013). In summary, drones are seen here as both the product and producer of novel regimes of "aerial governmentality" (Adey et al., 2013). One specific line of interrogation in this respect revolves around the security and regulatory issues that arise from the increasing occupation of airspace through public and private drones (Hale, 2009). Media-reported incidents of civil drones narrowly avoiding collisions with commercial airliners powerfully illustrate this problematic (Whitlock, 2014). Scholars have also shown how drones redefine the aerial sovereignty and supremacy of the State (Neocleous, 2013) and how they operate within, and affect, the national and international struggles between various powers over airspace (Aubout, 2011; Lacoste, 2011). William's work $(2011 \mathrm{~b}, 2013)$ is of particular interest here because it highlights that related strategies of aerial control and defence are as much about "looking down from above" as they are about "looking up from below", thus pointing at the need to approach the politics of the air enacted through and acting on drones in its complex and multidirectional spatialities, rather than as a merely downwards-oriented "vertical geopolitics" (Elden, 2013; Graham, 2004; Graham and Hewitt, 2013; Weizman, 2002). Future academic work should pursue this kind of reflection, so as to develop a vocabulary that goes beyond the emphasis on verticality, to capture more adequately the voluminosity and multi-dimensionality of the spaces of the air within which drones operate, and which drones contribute to perform.

Secondly, there have been some initial engagements with the specifically aerial characteristics of the drone gaze. This work investigates what difference it makes that drones operate in, from and through the air, if we are to understand their proliferation, functioning and implications. In addressing this question, scholars have inscribed drones in the long history of the "view from above", which reaches from aerial photography in archaeology to surveillance and bombing in warfare (Hough, 2013; Zaloga, 2008), and from the aerial policing of mega cities (Herbert, 1996; Adey, 2010) to the top-down visualities of aerial survey, photographic reconnaissance, remote sensing, satellite telemetry and GIS (Crampton, 2007). This work opens up a wide field of investigations into the evolutions, logics and power dynamics that characterise different modes of technologically mediated vision and visualization from above (Adey, 2010; Aubout, 2011). It also connects with wider efforts, especially in critical geopolitics, to problematize the rationalities, normative agendas and "violent epistemologies" (Adey et al., 2013) inherent in the geo-graphing of the world from above $(\mathrm{O}$ Tuathail, 1996).

Thirdly, this line of argumentation then leads to another, theoretically oriented sub-theme that relates to the concepts of (air) power and (air) space more generally. Scholars have used the drone problematic as a prism through which to develop a fuller theorization of the two concepts, thus pointing at the role of the aerial dimension in the exercise of power across and within space (Adey et al., 2013), and inviting a deepened engagement with the ways in which the exercise of power on the air also acts on the ground (Elden, 2013). This line of thinking has the merit of opening up a more systematic reflection on the aerial realm as a geopolitical space and indeed on space as a three-dimensional, spherical volume, rather than as a planar surface (Butler, 2001; Kaplan, 2006; Omissi, 1990; Williams, 2011a). However, it has yet to be deepened and informed more systematically by empirical material so as to afford more expansive insights into the volumetric geopolitics of the air, to which both public and private drone uses contribute.

\subsection{Politics of the ground}

A third theme that shapes academic engagement with the drone problematic consists in the exploration of the articulations, logics and implications of the drone gaze as it "falls" on the ground. Combined with the two aforementioned threads of research on drones as politics of visibility and as politics of the air, this literature offers an understanding of drones as windows on reality that are intrinsically bound up with space (here understood in both its aerial and earthly dimensions). In what follows, three interrelated logics that characterise the earthbound, spatially articulated drone gaze are discussed through the lens of the existing academic work, referring to distancing, mobility and flexibility (Wall, 2013).

\subsubsection{Distancing}

Drones operate at a spatial distance, both vertically and horizontally speaking (Bishop and Phillips, 2002; Wall and Monahan, 2011). The resulting dichotomy between "control 
spaces" and "controlled spaces" raises a series of power issues that have been subjected to academic scrutiny. Referring to military drones, for example, Gregory (2011), Chamayou (2013) and Wall (2013) problematize the asymmetries produced by the fact that the aircrafts allow their users "to be able to kill without being able to be killed; to be able to see without being seen. To become absolutely invulnerable while the other is placed in a state of absolute vulnerability" (Chamayou, 2011). From an empirical viewpoint, authors have foregrounded the operators' lived experience of the complex "geographies of proximity and reach" (Allen, 2003) that emerge from the drones' capacities of seeing and envisioning from afar (Gregory, 2011; Urry, 2014). Williams' work here is to show on rare empirical grounds how the distancing of military drone aircrews from the sites of war affects the very exercise of military power, and how the specific spaces of power enabled by drones are performed through the embodied geopolitical experiences of their remote aircrews (Williams, 2011b). Furthermore, scholars also refer to the distance and limited visibility from the ground of drones to explain the lack of public awareness of the aircrafts' use and development (Bracken-Roche et al., 2014). An important finding from these studies is that drones imply not only a spatial, but also a social and mental distance. People do not and cannot know the exact modalities and aims of specific drone systems, and they therefore cannot be sensitive to all of the issues at stake, although in some cases individuals knowingly either participate in their own monitoring through drones, resist drones, or use drones themselves as a form of countersurveillance (Schmidt, 2015). This finding resonates with the literature that questions contemporary techno-mediated forms and formats of control from the point of view of privacy and personal autonomy. As Rössler argues, personal autonomy may be fundamentally threatened if people are structurally mistaken about the possibility that other people may have information about them (Rössler, 2001). Future academic work on drones should thus help to more fully inform citizens, public agencies and the private sector of the various dimensions and effects of drones.

\subsubsection{Mobility}

Drones are also fundamentally mobile (Graham and Hewitt, 2013; Cogarty and Hagger, 2008). Indeed, as Wall and Monahan show (2011), the intrinsic mobility of drones is often placed centre stage in promotional discourses on drones, which stress the operational advancements of the aircrafts, with reference to their abilities to fly higher, further, and for a longer time. Such appraisals substantiate the relevance of Jensen's claim for a framing of the drone problematic through the "mobilities turn" paradigm, so as to foreground more systematically how drones relate to, embrace, and manage everyday life mobilities (Jensen, 2015). More specifically, scholars have started to reflect on how the drone's mobile gaze relates to the fixed and moving objects it envisions and controls. Relevant work includes Klauser's discussion of the drone as a means of "surveillance on the move" that allows the management of flows across urban space (Klauser, 2013a), and Williams' account of drones for the monitoring of moving people and objects around and across fixed borders (Williams, 2007). Further academic engagements with the mobility of drones should focus on how the mobile gaze of drones complements and interacts with other means of vision and control that are anchored on the ground (Klauser, 2013a; Graham, 2010). Such work could open up a broader empirical and theoretical project, aimed at investigating and conceptualizing the complementarities and tensions between differing spatialities of control, relating to fixity and mobility, enclosure, and openness (Klauser, 2013b).

\subsubsection{Flexibility}

Many authors also stress the spatial flexibility of the drone gaze, depending on and responding to the pursued objectives and observed reality (Blackmore, 2005; Crandall, 2003; Singer, 2009). For example, drones allow the monitoring of multiple places simultaneously, on different geographical scales (by means of a zoom lens) and by combining different spatial logics, such as (1) the continuous observation of mobile objects (by following the object in the air) or of fixed connections and separations (by flying above transport networks or national borders for example), (2) the fixed monitoring of particular sites (buildings, nodal points), or (3) the zonal surveillance of diffuse phenomena through continuous sweeping. This spatial flexibility can be further extended through the integration of additional sensors or software (Wall and Monahan, 2011) and by incorporating drones within wider network-centric forms of warfare or policing (Graham, 2010). Importantly, the drones' ability to adapt, both functionally and spatially speaking, is often described to lay at the very heart of their current and future development (Philippens, 2013), and should thus be placed centre stage in future research on the topic.

Together, the drone literature referring to distancing, mobility and flexibility suggest that drones have essential spatial dimensions. Fitted with imaging capabilities, they combine various geographical scales and spatial logics of vision and visualization from above and afar; they offer flexible and mobile ways of monitoring, following and orchestrating flows of people and objects; and they allow the administration of wider urban areas and border regions. It follows that the drone gaze is in practice highly specific and selective, focusing on some portions of space rather than on others, which in turn produces novel forms of spatial differentiation and hierarchization (Gregory, 2011).

The preceding comments justify the politico-geographical approach advocated in the present paper. Yet to avoid any misunderstanding, the space and power sensitivity endorsed here does not imply that other analytical levels of enquiry into the drone problematic should be neglected. On the con- 
trary, the preceding literature review as a whole reiterates the need to place centrally the political and socio-technical processes and relationships through which drone systems are conditioned and co-produced in order to understand their spatial logics and articulations (Klauser, 2013b).

\section{Towards a politico-geographical research agenda on drones}

Whilst the existing literature on drones is inspiring, it offers but preliminary and incomplete readings of the aforementioned problematics. For example, there is as yet no study that explores systematically how space contributes to the functioning and impacts of drones and how drones in turn affect the monitored and managed spaces. Equally, the discussed literature on drones as aero-visual techniques of power is yet to be developed more systematically and rigorously. Aside from these analytical shortcomings, there are at least three other important research gaps to highlight. Firstly, whilst there is a growing social scientific literature focusing on drones in military conflict, civil and commercial applications of the technology have remained widely unnoticed. Secondly, the existing academic work on drones suffers from a dramatic lack of empirical research, which explains the generalist tone and research focus that characterises most of the existing literature in the field. Thirdly, almost no social scientific studies exist that focus on drone practices in nonanglophone contexts. In Switzerland in particular, no social scientific research has been undertaken that explores the driving forces, functioning, and implications of drones, despite the rapid proliferation and advancements of the technology.

In what follows, we discuss three main analytical objectives that should be pursued in future research, that aims to provide a more solid understanding of the dynamics underpinning the current proliferation of drones, the modalities of use, and the resulting socio-spatial implications of the systems "put into action". Calling for detailed fieldwork, the hence emerging lines of investigation can be read as different levels of engagement with the crosscutting problematics outlined above, regarding the "politics of visibility", "politics of the air", and "politics of the ground". They in turn lead to a fourth, theoretically driven objective, revolving around the concepts of airpower and airspace.

\subsection{The making of drones}

The first analytical objective relates to the question of how, by whom and for what reasons, drone systems are planned, set up and subsequently put into practice. Hereby, emphasis should be placed not only on the actor networks and collaborations through which drone projects are co-produced, but also on the domains of expertise and sources of authority, expectations and beliefs that interact, fuse, emerge and crystallise around particular systems. Against this background, a broader reflection with regard to the processes and inter- actions (bringing together civil-military and public-private realms) that condition the current proliferation and diversification of drone practices can be advanced.

- How, by whom and for what reasons are drone systems assembled and "put into action" in different institutional settings and sites?

- How do particular forms of expertise and bodies of knowledge become authorized to act in the coproduction of specific drone projects? What does this tell us about the power structures built into the drone systems from the very project stage?

- How do particular actors, forms of authority, and interests, coalescing in the making of drone projects, affect the visual, aerial, and spatial logic of the drone gaze, thus contributing to the politics of visibility, politics of the air, and politics of the ground conveyed by the systems?

\subsection{The functioning of drones}

The second analytical objective consists in the exploration of the socio-technical mediations that underpin and condition the functioning of drone systems in operation. This analytical strand incorporates questions of how and for what reasons drones are used in different institutional settings and sites, how drone practices are mediated by various micro negotiations and decisions, and how issues of power and control are effectively actualized within everyday drone uses. In sum, the point here is to study the organizational settings, the situated coalitions of authority and indeed the manifest and latent functionalities and ambitions that shape the visual, aerial and spatial logics of drone systems in their everyday use. A geographically-relevant sub-aspect then concerns the question of how (air) space itself, as a socially produced reality, mediates specific drone operations and the visibilities hence created.

- What human and non-human actants participate in drone operations, thus mediating the aerial, visual and spatial logics of the systems in action?

- How are drone operations integrated within, and how in turn do they contribute to, existing regimes of aerial governmentality?

- What does this in turn tell us about the relation between drones and the airspace in which they operate?

\subsection{The implications of drones}

The third analytical objective relates to the question of how drones enable action upon, and thus impact on, the envisioned reality. In this, what matters is not only to provide isolated insights into the acting of drones in/on particular sites, 
but to re-institute this question as part of a broader set of analytical problems, relating to the power dynamics unfolding from the visual, aerial, and spatial logics of particular drone systems. An important sub-question thereby relates to the specific spatial trajectories along which power is exercised - or challenged - by public and private drones through and within the air. Yet, this objective also implies an approach that moves beyond the recognition of the spatial articulations of the drone gaze, to focus instead on how the aircrafts' view from above enables action on particular places, thus affecting practices and socio-spatial relations on the ground.

- What do drones allow their users to do? And what does this tell us about the benefits and problems associated with the proliferating drone gaze in the present-day world?

- How do drones redefine existing practices of policing, risk management, commercial filming, and so forth?

- What power and regulatory dynamics do contemporary drone uses imply? And how are drones intervening in the governing of everyday life, thus shaping particular places and affecting socio-spatial relations?

\subsection{Redefining (air) power and (air) space}

From the preceding analytical objectives arises a fourth, theoretical aspiration that seems central to us, relating to the concepts of (air) power and (air) space. We thus suggest the use of the drone problematic as a prism through which to advance new conceptual understandings of the performed and performative dimensions of space, approached as a "volume" composed of aerial and earthy realms rather than as a "planar surface". More specifically, the aim here is to more fully theorise the role of the aerial dimension in the projection of power across and within space and indeed to open up a reflection on the very possibility of a properly three-dimensional or volumetric type of political geography.

- What does the drone problematic tell us about the relation between (air) power and (air) space? And what do we learn regarding the conceptualization of the two terms?

- How can we conceptualise the relationship between the conjoined environments of land and air and how, and indeed through what vocabulary, are we to grasp theoretically and empirically the three-dimensionality of space within which drones operate and which drones contribute to perform?

- In turn, what can we learn from this conceptual reflection with regard to the possibility, scope and basic vocabulary of a political geography that frames the spacepower nexus in three-dimensional terms?

\section{Importance of the proposed research agenda}

The objectives outlined above should not be regarded as a rigid or definitive road map for future research, but as an initial attempt to identify some of the most salient questions and issues associated with the drone problematic that require more sustained critical attention. We believe that future research oriented around these objectives could advance the literature reviewed previously in important ways. For one, such research could advance a significant gain for understanding the driving forces, functioning and effects of both public and private drone systems, thus moving beyond the predominant focus in current academic work on US and UK military drone stories. Furthermore, given the dramatic lack of proper fieldwork on the drone problematic, as argued previously, the research agenda advocated here would add both empirical depth and theoretical nuance to our understanding of the cross-cutting visual, aerial, and spatial logic and power dynamics conveyed by the drone gaze, thus affording exemplary insight into the changing regimes of control and visibility that characterize the present-day world. Theoretically speaking, a research program along the lines outlined above could contribute substantially to the re-conceptualization of space as a spherical volume, rather than as a planar surface. This in turn might well lead to a reflection on the very possibility, scope, and basic vocabulary of a properly threedimensional political geography.

Of course, further empirical investigation into the drone problematic would also present huge potential to inform contemporary action and reflection on the drone problematic in politics, professional circles and across civil society more generally. Indeed at this very moment, relevant debates appear to be at a crossroad where important political and legal decisions are taken. Consider the European level, where quick action has been urged to be launched, so as to enable the progressive integration of drones into civil airspace from 2016 onwards (European Commission, 2014). In Switzerland, the legal framework for drones was revised substantially in 2014. Furthermore, cantons and cities have started to implement temporary or permanent legal provisions to regulate the use of private drones, especially at highrisk events. Media-reported examples include the cantons of Zurich, Geneva, Basel, Zug and Grisons. Further reflection is under way in the Federal Office of Civil Aviation (FOCA) on the regulatory and societal challenges associated with the proliferating use of drones, regarding refining and extending the existing legal framework in the fields of civil aviation and data protection most notably (Federal Office of Civil Aviation, 2014). This reiterates powerfully the topicality and importance of the suggested research agenda.

More generally speaking, in interrogating the making, functioning and implications of drones, the research we are advocating here connects neatly with broader contemporary debates on civil liberties, privacy, and security issues, threats of terrorism, policing, and the digitization of society. 
What matters most if we are to advance these debates, we believe, is to "open up" through sustained empirical research the usually hidden world that lies behind the ever more sophisticated technological systems that monitor, control, but also manage and enable everyday life. This is precisely the goal of the outlined research agenda.

Edited by: B. Korf

Reviewed by: three anonymous referees

\section{References}

Adey, P.: Vertical security in the megacity legibility, mobility and aerial politics, Theor. Cult. Soc., 27, 51-67, 2010.

Adey, P., Whitehead, M., and Williams, A. J.: Introduction: Airtarget: Distance, reach and the politics of verticality, Theor. Cult. Soc., 28, 173-187, 2011.

Adey, P., Whitehead, M., and Williams, A. J.: From Above: War, Violence, and Verticality, Hurst Publishers, London, 2013.

Allen, J.: Lost Geographies of Power, Blackwell, Oxford, 2003.

Asencio, M.: L'utilisation civile des drones: Problèmes techniques, opérationnels et juridiques, Sécurité Globale, 109-118, 2008.

Aubout, M.: Le milieu aérien, acteur et objet du renseignement, Hérodote, 81-90, 2011.

Baconnet, A.: Au pays des drones, Outre-Terre, 245-248, 2014.

Birmingham Policy Commission: The security impact of drones: Challenges and opportunities for the UK, University of Birmingham, 2014.

Bishop, R. and Phillips, J.: Unmanning the homeland, Int. J. Urban Regional, 26, 620-625, 2002.

Blackmore, T.: War X: Human extensions in battlespace, University of Toronto Press, Toronto, 2005.

Bracken-Roche, C., Lyon, D., James Mansour, M., Molnar, A., Saulnier, A., and Thompson, S.: Surveillance drones: Privacy implications of the spread of unmanned aerial vehicles (UAVs) in Canada. A report to the office of the privacy commissioner of Canada, under the 2013-2014 contributions program, Surveillance Studies Centre, Queen's University, 2014.

British Ministry of Defence: The UK approach to unmanned aircraft systems, 2011.

Brouet, A.-M.: La bande d'arrêt d'urgence active fait ses preuves, EPFL, 2014.

Butler, D. L.: Technogeopolitics and the struggle for control of world air routes, 1910-1928, Polit. Geogr., 20, 635-658, 2001.

Canal, L.: Le marché des drones en plein boom, Bilan, 2014.

Chamayou, G.: The manhunt doctrine, Radical Philos., 169, 2-6, 2011.

Chamayou, G.: Théorie du Drone, La fabrique, Paris, 2013.

Clarke, R.: The regulation of civilian drones' impacts on behavioural privacy, Computer Law \& Security Review, 30, 286305, 2014.

Cogarty, B. and Hagger, M.: The laws of man over vehicles unmanned: The legal response to robotic revolution on sea, land and air, Journal of Law, Information and Science, 19, http: //www.austlii.edu.au/au/journals/JlLawInfoSci/2008/5.html (last access: 2 October 2015), 2008.

Cox, K. R., Low, M., and Robbinson, J.: Political geography: Traditions and turns, in: The Sage Handbook of Political Geography, edited by: Cox, K. R., Murray, L., and Robinson, J., Sage, London, 1-14, 2008.

Crampton, J. W.: The biopolitical justification for geosurveillance, Geogr. Rev., 97, 389-403, 2007.

Crandall, J.: Unmanned. Embedded reporters, predator drones and armed perception, ctheory.net (last access: 2 October 2015), 2003.

Delaye, F.: Ces drones suisses qui veulent faire la paix, Bilan, 2013.

Duruz, C.: Les pompiers d'Yverdon sont pionniers dans l'usage d'un drone, Tribune de Genève, 2014.

Elden, S.: Secure the volume: vertical geopolitics and the depth of power, Polit. Geogr., 34, 35-51, 2013.

European Commission: A new era for aviation: Opening the aviation market to the civil use of remotely piloted aircraft systems in a safe and sustainable manner, Communication from the commission to the European Parliament and the Council, Brussels, 2014.

Federal Office of Civil Aviation: Où ai-je le droit de faire voler mon multicoptère?, FOCA, 2014.

Finn, R. L. and Wright, D.: Unmanned aircraft systems: Surveillance, ethics and privacy in civil applications, Computer Law \& Security Review, 28, 184-194, 2012.

Fleury, P.: L'armée suisse veut remplacer ses vieux drones par six appareils, Le Nouvelliste, 2013.

Geiger, H.: The drones are coming, Center for Democracy and Technology, 2011.

Gessat, R.: Smart border's - Europe's new high-tech frontiers, Deutsche Welle, 2012.

Gettinger, D., Michel, A. H., Pasternack, A., Koebler, J., Musgrave, S., and Rankin, J.: The Drone Primer. A Compendium of the Key Issues, edited by: drone, C. f. s. o. t., Bard College, 2014.

Goodman, M.: A view from the unfriendly skies: How criminals are using drones, TED, 2013.

Graham, S.: The Cybercities Reader, Psychology Press, London, 2004.

Graham, S.: Cities under Siege: The New Military Urbanism, Verso, London, 2010.

Graham, S. and Hewitt, L.: Getting off the ground: On the politics of urban verticality, Prog. Hum. Geogr., 37, 72-92, 2013.

Gregory, D.: From a view to a kill drones and late modern war, Theor. Cult. Soc., 28, 188-215, 2011.

Hale, J.: Intégrer les drones dans l'espace aérien civil de l'UE, Europolitique, 2009.

Herbert, S.: The geopolitics of the police: Foucault, disciplinary power and the tactics of the Los Angeles Police Department, Polit. Geogr., 15, 47-59, 1996.

Homeland Security News Wire: Teal Group: Global UAV market to total $\$ 94$ billion in the next ten years, Homeland Security News Wire, 2011.

Hough, K.: Aerial torpedoes, buzz bombs, and predators: The long cultural history of drones, Origins, 6, http://origins.osu.edu/article/aerial-torpedoes-buzz-bombsand-predators-long-cultural-history-drones (last access: 2 October 2015), 2013.

Information and Privacy Commissioner: Privacy and drones: Unmanned aerial vehicles, Ontario, Canada, 2012.

Jensen, O.: New "Foucaultdian boomerangs": Drones and urban surveillance Surveillance \& Society, under review, 2015. 
Kaplan, C.: Mobility and war: the cosmic view of USair power, Environ. Plann. A, 38, 395-407, 2006.

Klauser, F. R.: Spatialities of security and surveillance: Managing spaces, separations and circulations at sport mega events, Geoforum, 49, 289-298, 2013a.

Klauser, F. R.: Political geographies of surveillance, Geoforum, 49, 275-278, 2013b

Lacoste, Y.: Renseignement et intelligence géographique, Hérodote, 140, 3-8, 2011.

Latour, B.: Reassembling the Social: An Introduction to ActorNetwork-Theory, Oxford University Press, Oxford, 2005.

Lauener, P.: Cachez ce drone... L'Hebdo, http://www.hebdo.ch/ hebdo/cadrages/detail/cachez-ce-drone\%E2\%80\%A6 (last access: 2 October 2015), 28 August 2014.

Lyon, D.: Surveillance Studies: An Overview, Polity Press, Cambridge, 2007.

Mayfield, T. D.: Digitization of the battlefield: Operational implications for the U.S. army in multinational operations, United States army command and general staff college, Fort Leavenworth, Kansas, 1996.

Moulard, G. and Grozel, M.: Drones, Mystérieux Robots Volants, Lavauzelle, Panazol, 2008.

Murakami Wood, D., Ball, K., Lyon, D., Norris, C., and Raab, C.: A report on the surveillance society, Information Commissioner Office, London, 2006.

Neocleous, M.: Air power as police power, Environ. Plann. D, 31, 578-593, 2013.

Nimmo, K.: Nanny Bloomberg: Drone panopticon inevitable, http://www.infowars.com/ nanny-bloomberg-drone-panopticon-inevitable/ (last access: 2 October 2015), 2013.

O Tuathail, G.: Critical Geopolitics, Routledge, London, 1996.

Office of the Privacy Commissioner of Canada: Drones in Canada. Will the proliferation of domestic drone in Canada raise new concerns for privacy?, Gatineau, Canada, 2013.

Omissi, D. E.: Air Power and Colonial Control: The Royal Air Force, 1919-1939, University Press, Manchester, 1990.

Painter, J.: Geographies of space and power, in: The Sage Handbook of Political Geography, edited by: Cox, K. R., Murray, L., and Robinson, J., Sage, London, 57-72, 2008.

Pedrozo, S.: Entre utilisation militaire et civile des drones: Étude critique de la surveillance mobile et aérienne en Suisse, $\mathrm{PhD}$ outline, Neuchâtel University, non published, 2014.

Philippens, H.: Drones and deterrence: How robotics will impact strategic stability, Royal United Services Insitute 1-12, 2013.

Raffestin, C.: Pour une Géographie du Pouvoir, Litec, Paris, 1980.

Rey-Mermet, A.: Des drones modélisent le Cervin en 3D, 24 heures, 2013.

Rössler, B.: Der Wert des Privaten, Suhrkamp, Frankfurt, 2001.

Rothstein, A.: Drone, Bloomsbury, New York, 2015.
RTS: Les drones civils au regard de la loi, On en Parle [Audio], 30 September 2014.

Sacco, F.: Premier coup de frein aux drones civils, Le Temps, 2014.

Schmidt, H.: From a bird's eye Perspective: Aerial drone photography and political protest. A Case study of the Bulgarian resign movement, Digital Icons, Studies in Russian, Eurasian and Central European New Media, 13, 1-27, 2015.

Schweizer Armee: Bulletin Flugplatzkommando Emmen, Bern, Schweizerische Eidgenossenschaft, 2008.

Singer, P. W.: Wired for War: The Robotics Revolution and Conflict in the 21st Century, Penguin Press, London, 2009.

Stanley, J. and Crump, C.: Protecting Privacy from Aerial Surveillance: Recommendations for Government Use of Drone Aircraft, American Civil Liberties Union, 2011.

Turrettini, E.: Comment les drones sont utilisés dans le civil, Bilan, 2013.

United States Government Accountability Office: Nonproliferation. Agencies could improve information sharing and end-use monitoring on unmanned aerial vehicle exports, Washington, DC, 2012.

Urry, J.: Offshoring, Polity, Cambridge, 2014.

Valavanis, K. P. and Vachtsevanos, G. J.: Handbook of Unmanned Aerial Vehicles, Springer, the Netherlands, 2015.

Virilio, P.: The Information Bomb, Verso, London, 2000.

Wall, T.: Unmanning the police manhunt: Vertical security as pacification, Socialist Studies, 9, 32-56, 2013.

Wall, T. and Monahan, T.: Surveillance and violence from afar: The politics of drones and liminal security-scapes, Theor. Criminol., 15, 239-254, 2011.

Weizman, E.: Control in the air, Open Democracy, 2002.

Whitlock, C.: Near-collisions between drones, airliners surge, new FAA reports show, The Washington Post, 2014.

Williams, A. J.: Hakumat al Tayarrat 1: The role of air power in the enforcement of Iraq's boundaries, Geopolitics, 12, 505-528, 2007.

Williams, A. J.: Enabling persistent presence? Performing the embodied geopolitics of the unmanned aerial vehicle assemblage, Polit. Geogr., 30, 381-390, 2011 a.

Williams, A. J.: Reconceptualising spaces of the air: performing the multiple spatialities of UK military airspaces, T. I. Brit. Geogr. 36, 253-267, doi:10.1111/j.1475-5661.2010.00416.x, 2011b.

Williams, A. J.: Re-orientating vertical geopolitics, Geopolitics, 18, 225-246, 2013.

Wise, J. M. and Koskela, H.: New Visualities, New Technologies, The New Ecstasy of Communication, Ashgate, London, 2013.

Zaloga, S.: Unmanned Aerial Vehicles: Robotic Air Warfare 19172007, Osprey Publishing, Oxford, 2008.

Zubeldia, O.: Histoire des Drones, Perrin, Paris, 2012. 